\section{Fontan on stage: The year 2020}

\author{
Can Yerebakan, MD, and Yves d'Udekem, MD
}

We have mastered unprecedented challenges during the 2020 pandemic, with uninterrupted and steadily excelling service to our patients and community. Our profession in adult and congenital heart surgery has rapidly overcome the severe initial impact of the pandemic on our daily work and absorbed several aftershocks in the rapidly evolving preoperative clinical presentation of our patients due to ongoing pandemic conditions worldwide. Meanwhile, teams were relentlessly striving to keep producing top-notch results in research to prevent any interruption to this most essential requirement of the future of our profession. Here, we highlight the most impactful articles published from American Association for Thoracic Surgery journals and beyond on Fontan circulation during 2020.

The optimization of the Fontan circulation as the final touch in single-ventricle palliation remains among the most visited research questions in our field. The excellence in single-ventricle palliation at each step has ultimately increased the number of patients living with Fontan circulation. While creating the best possible Fontan candidates, we also strive for perfection in surgically creating the immaculate Fontan circulation. The extensive experience in different types of total cavopulmonary connection help us to analyze the latest outcomes with large patient numbers.

This year, Weixler and colleagues ${ }^{1}$ from Boston contributed to the continued discussion with a close to 20-year experience with more than 800 patients by a retrospective view on long-term results of 2 widely used Fontan modifications. At a median follow-up time of 4.8 years, lateral tunnel Fontan patients $(\mathrm{n}=638)$ had better survival and freedom from Fontan failure than extracardiac Fontan modification $(n=163)$ after correcting for several confounding factors. ${ }^{1}$ Excellent outcomes have recently been reported by Stephens and colleagues ${ }^{2}$ in 341 patients with nonfenestrated extracardiac Fontan and Fontan conversions, whereas preoperative ventricular function was shown to influence long-term freedom from takedown, death, and transplant. Analyses of outcomes of subgroups of patients

\footnotetext{
From the Division of Cardiac Surgery, Children's National Heart Institute, The George Washington University School of Medicine and Health Sciences, Washington, DC.

Received for publication April 13, 2021; revisions received April 13, 2021; accepted for publication April 15, 2021; available ahead of print April 22, 2021.

Address for reprints: Can Yerebakan, MD, Division of Cardiovascular Surgery, Children's National Heart Institute, Children's National Hospital, The George Washington University School of Medicine and Health Sciences, 111 Michigan Ave, NW, Washington, DC 20010 (E-mail: cyerebakan@childrensnational.org).

J Thorac Cardiovasc Surg 2021;162:369-71

$0022-5223 / \$ 36.00$

Copyright (C) 2021 by The American Association for Thoracic Surgery https://doi.org/10.1016/j.jtcvs.2021.04.047
}

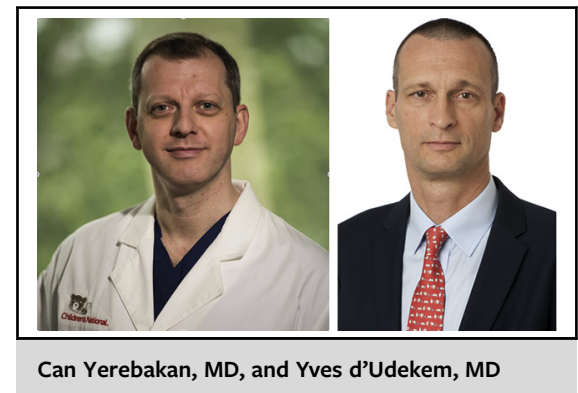

\author{
CENTRAL MESSAGE \\ This article aims to highlight \\ most impactful articles extracted \\ from American Association for \\ Thoracic Surgery journals and \\ beyond on Fontan circulation \\ during 2020.
}

with a Fontan circulation aid in understanding risk profiles in an evidenced-based setting. Patients with heterotaxy syndrome are known to have inferior outcomes in singleventricle palliation in comparison to those without heterotaxy. However, a meta-analysis of 848 patients shows that once these patients are safely palliated to a Fontan completion, their long-term survival is comparable to overall Fontan cohorts. ${ }^{3}$ The candidates in the quest for the best Fontan modification remain on stage because we have started to gain insight into what extent subtle hemodynamic changes may influence the long-term outcome of these patients. The expert team of Yoganathan and colleagues ${ }^{4}$ provides the results of their detailed of postoperative magnetic resonance imaging in 10 Fontan patients with commercially available Y-graft connections. Y-grafts may provide a better hemodynamic profile, providing a more stable resistance in the circuit and a more balanced hepatic flow distribution over time than the conventional extracardiac patient group at 3-year follow-up. In an effort to improve long-term outcomes, preoperative estimates of the ideal conditions for a Fontan circulation can already be provided by computer-aided design and computational fluid dynamics simulations. Loke and colleagues ${ }^{5}$ move 1 step ahead and propose a concept of adding surgeons' expertise to the computerized design for an optimization of the Fontan conduit in a patient-specific strategy. With this new approach, the advantages of computer-aided creation of a hemodynamically 
optimal conduit can be combined with a surgeon's unconstrained modeling and may result in the overall best Fontan constellation.

Despite ongoing efforts, a failing Fontan circulation remains a challenge for clinicians. Pathophysiologic effects of a chronic hypertension in the systemic venous system lead to dysfunctional lymphatic drainage with deleterious long-term consequences. Among the ingenious procedures proposed for this conundrum is the innominate vein turndown procedure, which may decompress the lymphatic system with improved symptoms of lymphatic complications. ${ }^{6}$

Mechanical circulatory support for these patients may offer an alternative for a successful bridge to transplantation. A multicenter registry analysis of the Advanced Cardiac Therapies Improving Outcomes Network reveals the results of continuous flow-assist device support, including patients with congenital heart disease and Fontan failure.

\section{CONCLUSIONS}

Surgical optimization of the third and final stage of palliation in single-ventricle circulation continues to remain in the focus of clinicians and research teams. During 2020, large single-center outcome analyses were accompanied by excellent translational efforts of preclinical research studies with the implementation of advanced imaging and computer-aided techniques in attempt to find solutions for suboptimal physiological aspects of current Fontan strategies.

\section{Conflict of Interest Statement}

The authors reported no conflicts of interest.

The Journal policy requires editors and reviewers to disclose conflicts of interest and to decline handling or reviewing manuscripts for which they may have a conflict of interest. The editors and reviewers of this article have no conflicts of interest.

\section{References}

1. Weixler VHM, Zurakowski D, Kheir J, Guariento A, Kaza AK, Baird CW, et al. Fontan with lateral tunnel is associated with improved survival compared with extracardiac conduit. J Thorac Cardiovasc Surg. 2020;159:1480-91.e2.

2. Stephens EH, Talwar AA, Devlin PJ, Eltayeb O, Mongé MC, Tsao S, et al. 24-Year results of nonfenestrated extracardiac fontan including fontan conversions. Ann Thorac Surg. August 11, 2020 [Epub ahead of print].

3. Marathe SP, Cao JY, Celermajer D, Ayer J, Sholler GF, d'Udekem Y, et al. Outcomes of the Fontan operation for patients with heterotaxy: a meta-analysis of 848 patients. Ann Thorac Surg. 2020;110:307-15.

4. Trusty PM, Wei Z, Sales M, Kanter KR, Fogel MA, Yoganathan AP, et al. Y-graft modification to the Fontan procedure: increasingly balanced flow over time. $J$ Thorac Cardiovasc Surg. 2020;159:652-61.

5. Loke YH, Kim B, Mass P, Opfermann JD, Hibino N, Krieger A, et al. Role of surgeon intuition and computer-aided design in Fontan optimization: a computational fluid dynamics simulation study. J Thorac Cardiovasc Surg. 2020;160: 203-12.e2.

6. Hraska V, Mitchell ME, Woods RK, Hoffman GM, Kindel SJ, Ginde S. Innominate vein turn-down procedure for failing Fontan circulation. Semin Thorac Cardiovasc Surg Pediatr Card Surg Annu. 2020;23:34-40.

7. O'Connor MJ, Lorts A, Davies RR, Fynn-Thompson F, Joong A, Maeda K, et al. Early experience with the HeartMate 3 continuous-flow ventricular assist device in pediatric patients and patients with congenital heart disease: a multicenter registry analysis. J Heart Lung Transplant. 2020;39:573-9.

Key Words: Fontan circulation 


\section{Fontan on Stage: The Year 2020: Recent Articles From AATS Journals}
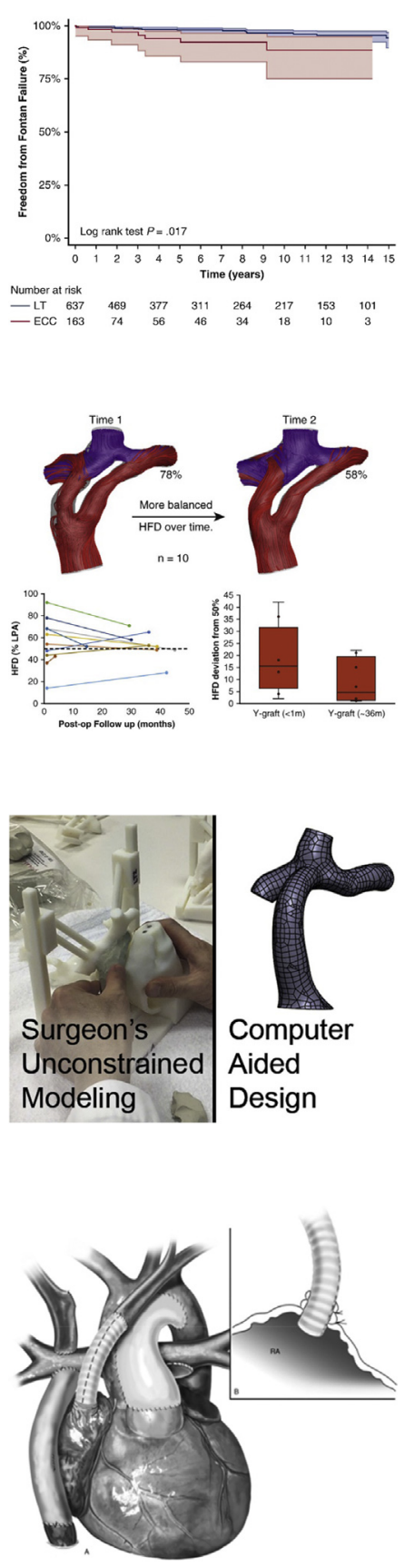

JTCVS: Fontan with lateral tunnel is associated with improved survival compared with extracardiac conduit. Weixler VHM, Zurakowski D, Kheir J, Guariento A, Kaza AK, Baird CW, Del Nido PJ, Emani SM. J Thorac Cardiovasc Surg. 2020;159(4):1480-1491. Commentary: I don't like change. Huddleston CB. J Thorac Cardiovasc Surg. 2020;159(4): 1491-1492.

JTCVS: Y-graft modification to the Fontan procedure: Increasingly balanced flow over time. Trusty PM, Wei Z, Sales M, Kanter KR, Fogel MA, Yoganathan AP, Slesnick TC. J Thorac Cardiovasc Surg. 2020;159(2):652-661.

Commentary: Why use the Y-graft? Si MS, Sood V, Bove E. J Thorac Cardiovasc Surg. 2020;159(2):662-664.

Commentary: Why the Y-graft? Schwartz SM. 2020;159(2):665-666.

JTCVS: Role of surgeon intuition and computer-aided design in Fontan optimization: A computational fluid dynamics simulation study. Loke YH, Kim B, Mass P, Opfermann JD, Hibino N, Krieger A, Olivieri L. J Thorac Cardiovasc Surg. 2020; 160(1):203-212.

Commentary: Yet another Fontan computational study-but this one has clay. Woods RK, Ginde S. J Thorac Cardiovasc Surg. 2020;160(1):213-214.

Commentary: A 3-minute foray into the future. DeCampli WM. J Thorac Cardiovasc Surg. 2020;160(1):214-215.

Commentary: Man versus machine: Whose side are you on? Hsia TY. J Thorac Cardiovasc Surg. 2020;160(1):216-217.

Ped Ann: Innominate vein turn-down procedure for failing fontan circulation. Hraska V, Mitchell ME, Woods RK, Hoffman GM, Kindel SJ, Ginde S. Semin Thorac Cardiovasc Surg Pediatr Card Surg Annu. 2020;23:34-40. 